Eixo Roda, Belo Horizonte, v. 29, n. 3, p. 19-35, 2020

\title{
Cláudio Grugel do Amaral e Frei Bernardo de Brito: sentidos da paródia
}

\section{Cláudio Grugel do Amaral and Friar Bernardo de Brito: Parody Meanings}

\author{
Francisco Topa \\ Universidade do Porto (U.Porto), Porto / Portugal \\ ftopa@letras.up.pt
}

http://orcid.org/0000-0001-6929-5618

Resumo: Cláudio Grugel do Amaral (Rio de Janeiro, c. 1681-Lisboa, 1752) é um poeta luso-brasileiro cuja obra, reunida num volume manuscrito, ficou inédita. De conteúdo globalmente satírico, a sua poesia - cuja edição será apresentada no decurso de 2020 constitui, pelo menos em parte, uma paródia de uma conhecida obra do quinhentismo português: Sílvia de Lizardo (1597), de Frei Bernardo de Brito (1569-1617). O artigo dá conta do diálogo entre o poeta brasileiro e o polígrafo português, tendo o cuidado de apresentar devidamente a desconhecida obra do primeiro.

Palavras-chave: Cláudio Grugel do Amaral; Frei Bernardo de Brito; poesia barroca; paródia.

Abstract: Cláudio Grugel do Amaral (Rio de Janeiro, c. 1681-Lisbon, 1752) is a LusoBrazilian poet whose work, assembled in a manuscript volume, remained unpublished. His poetry - whose edition will be presented in the course of 2020 - is globally satirical, and at least in part a parody of a well-known Portuguese 16th century book: Silvia de Lizardo (1597), by Friar Bernardo de Brito (1569-1617). The article gives an account of the dialogue between the Brazilian poet and the Portuguese polygraph, making sure to properly present Cláudio's unknown work.

Keywords: Cláudio Grugel do Amaral; Friar Bernardo de Brito; Baroque poetry; parody.

A morte do autor, proclamada por correntes teóricas diversas que vão do Formalismo Russo ao New Critiscism, veio a tornar-se uma linha de força do pós-estruturalismo, tendo hoje uma ampla aceitação na sua vertente aplicada mais simples, a da aversão ao uso da biografia como elemento explicativo do texto. Esse consenso não implica, contudo, a rejeição pura e 
simples de informações de tipo biográfico enquanto elemento importante - e até decisivo - para a contextualização de uma obra. É justamente um caso deste tipo que será abordado neste artigo.

Vou assim retomar, corrigindo e alargando, um trabalho de 2011 (TOPA, 2011) que deverá sair no próximo ano sob a forma de edição crítica. O ponto de partida é o Ms. 354 da Biblioteca Geral da Universidade de Coimbra, que apresenta a seguinte folha de rosto:

Folha de rosto do MS. 354 da Biblioteca Geral da Universidade de Coimbra

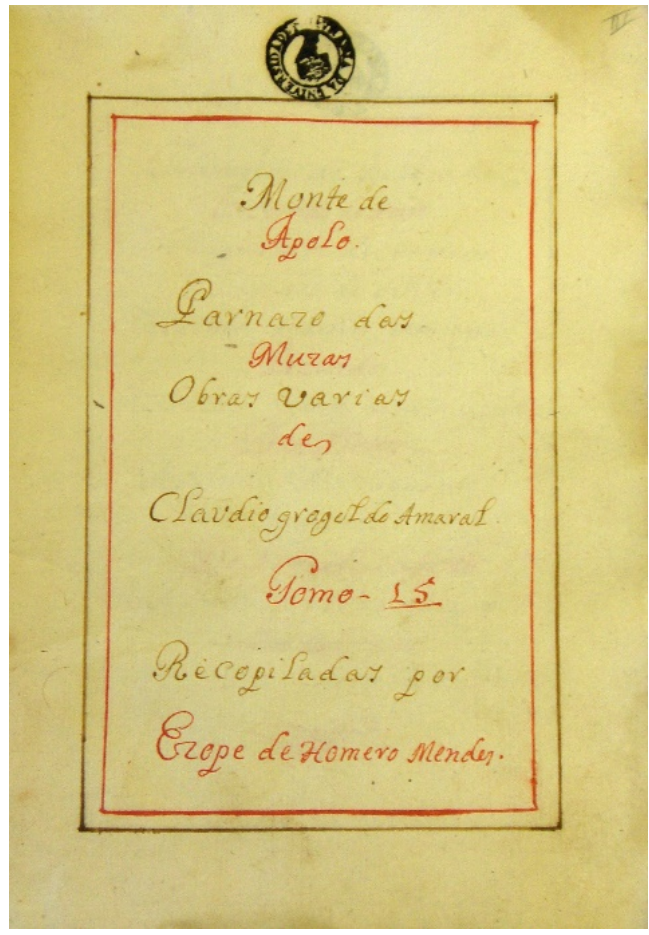

Fonte: Arquivo pessoal do autor

A inscrição engloba um título, um autor e um compilador: "Monte de/ Apolo./ Parnazo das/ Muzas/ Obras Varias/ de/ Claudio Grogel do Amaral./ Tomo - 15/ Recopiladas por Ezope de Homero Mendes." O título, a avaliar pelas metáforas mitológicas, parece apontar para uma obra poética, provavelmente de estilo barroco; a indicação de autoria pede uma identificação que não é imediata nem fácil; o cólofon tem um caráter um 
tanto ou quanto burlesco: não é de crer na veracidade de um compilador chamado "Ezope" e "de Homero"; o mesmo se pode dizer de "Tomo - 15", a menos que a indicação seja interpretada como fazendo referência a uma coleção com vários autores (e não, portanto, às obras de um mesmo "Claudio Grogel do Amaral"). A identificação do autor constitui um problema de difícil resolução que, como veremos, é importante para a leitura da obra como parte de uma tradição literária.

De acordo com aquilo que pude apurar até agora, há duas hipóteses de atribuição de uma identidade precisa àquele nome, ambas brasileiras (no sentido, pelo menos, de nascidas no Brasil, ou na América Portuguesa) e ligadas pelo laço familiar de tio-sobrinho. A informação consta de um artigo de Nuno Canas Mendes (2000) em que são estudados dois ramos da família Amaral Gurgel que vieram para Portugal.

O primeiro Cláudio era neto do fundador da família no Brasil, o corsário Toussaint Grugel, natural de Le Havre: a mãe do hipotético poeta, Ângela de Arão do Amaral, era filha do francês, tendo casado por volta de 1637 com o capitão João Baptista Jordão, natural de Azinhaga do Ribatejo. Cláudio Grugel do Amaral, o último dos sete filhos do casal, terá nascido por volta de 1654, no Rio de Janeiro, onde também morreria, assassinado, a 17 de abril de 1716. Veio para Coimbra estudar Cânones, matriculandose em Instituta a 8 de novembro de 1670, de acordo com Francisco Morais (1949, p. 29-30). Obteria, segundo o mesmo autor, o grau de Bacharel a 14 de maio de 1676, alcançando a Formatura a 22 de maio do ano seguinte. Este Cláudio Grugel publicou em Coimbra, em 1675, um texto jurídico em latim, ainda na qualidade de estudante: Ad Inchoanda Scholastica Certamina. Pontificii Juris Proponuntur Asseverationes (AMARAL, 1675). Verifica-se também, pela consulta do trabalho de Ángel Marcos de Dios (2001, p. 105), que Cláudio Grugel frequentou igualmente a Universidade de Salamanca. Nessa universidade obtivera aliás o bacharelato em Cânones a 2 de maio de 1675 (livro 752, f. 161v).

A 25 de junho de 1679 está de regresso ao Rio de Janeiro, de onde dirige uma carta ao Dr. André Nunes da Silva que encontrei na Biblioteca Nacional de Portugal (Ms. 245, n. 141). O destinatário da missiva é um poeta de certo relevo do período barroco que viveu entre 1630 e 1705 . Segundo Diogo Barbosa Machado (1731, I, p. 156-158), André Nunes da Silva terá ido, em tenra idade, com os seus pais para o Rio de Janeiro, 
onde frequentaria o colégio dos Jesuítas. Regressaria a Portugal em julho de 1650, com o objectivo de frequentar o curso de Direito Canónico na Universidade de Coimbra. Obteria o grau de bacharel em 1656, sendo mais tarde ordenado sacerdote. Enquanto poeta, destacou-se como membro da Academia dos Singulares e da Academia dos Generosos, publicando diversas obras e deixando outras inéditas.

A carta de Cláudio trata de diversos assuntos quotidianos e de uma encomenda de livros, não tendo por isso particular interesse para o assunto em questão, que é a autoria do volume manuscrito que se guarda em Coimbra. De qualquer modo, é possível notar que se trata de um texto que revela domínio da escrita e cultura literária, embora esse dado não sirva de elemento de prova, na medida em que se trata de um requisito habitual num bacharel formado em cânones por Coimbra (e Salamanca). Veja-se contudo, a título meramente ilustrativo, o primeiro parágrafo:

\section{Meu Sr.,}

É certo que se não logram ditas neste mundo sem que ao mesmo tempo se experimente algum dissabor, que as faz não chegar ao auge da perfeição, porque como nele é tudo aparente e defeituoso tudo, ainda o que se mostra mais firme e mais perfeito padece as faltas, que bastam a diminuir-lhe a grandeza com que se nos representa; assim me sucede agora com o que me propunha o discurso ao tempo em que me embarquei e com o que a experiência me ensina, quando me vejo logrando a pátria (que não sei se suspirei com muita ânsia), cuja vista me alegrou de sorte que cheguei a julgar bem empregadas todas as aflições passadas, só pelo bem presente; porém, como este se não logra sem desares, era força que me sucedesse quando o possuo[,] o que é tão comum a todos; mas bem me rira eu desta regra tão geral, se não fora a saudade de V. M. a que perturba o contentamento com que me vejo, porque só ela sendo efeito do afeto com que estimo a V. M. pudera opor-se a tamanha ventura; ainda eu pudera continuar esta matéria apoiando a verdade do que digo, se não fora conhecer o crédito que $\mathrm{V}$. M. dá à minha amizade e à fineza com que o venero, $\mathrm{e}$ assim me livro de mais rezões e a V. M. de tanta leitura. (AMARAL, 1679, Ms. 245, n. 141)

Sabe-se ainda que Cláudio casaria, em 1684, com a carioca Ana Barbosa da Silva, resultando dessa união quatro filhos. Por alvará régio de 12 de fevereiro de 1688, seria nomeado Provedor da Fazenda do Rio de Janeiro e desempenharia outras funções públicas, designadamente as de 
Vereador da Câmara e de Provedor da Santa Casa da Misericórdia. Ocupou ainda, de acordo com Heitor Amaral (1964, p. 72-75), uma série de lugares relativos à defesa militar do Rio de Janeiro. Tendo ficado viúvo a 2 de abril de 1695, abraçou a vida sacerdotal, aparecendo mais tarde envolvido num aventuroso episódio político-policial com o seu segundo filho, o Alferes José Grugel do Amaral. De contornos ainda mal esclarecidos, o caso parece ter tido a ver com a oposição - tanto de Cláudio como de seu filho José - ao Governador do Rio de Janeiro Francisco Xavier de Távora, que exerceu o cargo entre 1713 e 1716. O ponto alto do conflito foi a morte de João Manuel de Melo, favorito do Governador, às mãos do Alferes José. A vingança desse homicídio acabaria por provocar a morte de Cláudio Grugel do Amaral, enquanto o filho - logrando escapar desta feita - viria a ser executado na Baía, em 1722.

Mesmo com o episódio que acabaria por provocar a sua morte, talvez não haja na biografia do possível poeta nada de absolutamente excecional: produto da elite local, obtém formação superior em Portugal, volta à terra de origem, atuando como um homem do seu estatuto e da sua época, não hesitando em assumir o conflito com as autoridades que limitavam o seu poder.

Vejamos agora a outra possibilidade de identificação, correspondente ao sobrinho homónimo do precedente. Este segundo Cláudio, de acordo com Nuno Canas Mendes (2000, p. 246), nasceu também no Rio de Janeiro, por volta de 1681, e faleceu em Lisboa, a 19 de março de 1752. Estudou igualmente em Coimbra, obtendo o grau de Bacharel em Cânones, mas acabou por fixar residência em Lisboa, sendo nomeado Procurador da cidade em 1704. Mais tarde, em 1737, seria nomeado Superintendente da Junta da Administração das Obras das Águas Livres, assumindo um papel de grande relevo na resolução do problema de abastecimento de água à capital. Tinha casado em 1702 com Brites Teresa de Melo, natural de Maragojipe, no Recôncavo baiano.

Para além destes elementos biográficos, temos no próprio cancioneiro dois dados indiretos. O primeiro vem num poema (f. $38 \mathrm{v}$ ) em que o sujeito declara ter nascido em Portugal: 
A ũa Senhora, que murmurava de Lisardo não fazer a Sílvia versos senão em Português

Soneto

Em Portugal nasci, me diz o Cura, em Portugal me fiz, tal qual Poeta, parir podia minha Mãe em Creta e falar-te-ia em língua mais escura;

Que te pareça pois por desventura a Musa em português não ser discreta, pouco vai, porque a musa de um baieta teus fileles na lima não procura;

Eu poeta (se sou) como enamoro a Sílvia mais gentil, em a beleza Anjo humanado, em o terreno Coro;

Sendo Sílvia tão linda Portuguesa, fora, Senhora Aminta, desaforo o fazer-lhe eu os versos à Francesa.

Num outro momento da obra, há um texto em décimas em que um conjunto de damas, dirigindo-se a Lisardo, o dão "por Cabrão em Portugal,/ Conde de Cabra em Castela." (f. 60). Aliás, já o autor do poema que serve de prólogo se referira ao autor como "excelso lusitano".

Não creio que elementos deste tipo ponham em causa a autoria de qualquer dos dois Cláudios atrás referidos: nascidos no Rio de Janeiro, são brasileiros mas não deixam de ser portugueses, não sendo portanto de estranhar que o sujeito diga "Em Portugal nasci [...]", sobretudo num contexto em que justifica e defende a utilização da língua portuguesa. Aliás, o facto de afirmar que "em Portugal me fiz, tal qual Poeta" parece sugerir que a prática da poesia se iniciou com a vinda para Coimbra. Por outro lado, o conteúdo burlesco de parte da obra e a ausência de quaisquer referências ao Brasil no seu conjunto talvez autorizem a supor que a atividade poética do autor, qualquer que ele seja, se limitou ao período estudantil. Um último argumento obriga a antecipar o ponto principal deste breve estudo: a relação - paródica - da obra manuscrita com a Sílvia de Lisardo, de Baltasar de Brito e Andrade, mais conhecido pelo seu nome religioso de Frei Bernardo 
de Brito. De facto, no prólogo do impressor que vem na 1. ${ }^{\mathrm{a}}$ edição de Sílvia, de 1597, há também uma defesa da língua portuguesa:

Ficãdome de tudo ifto o premio de ver a lingoa Portugue $\int a$ engrandecida com impre $\iint o$ ẽs, \& conhecida por e $\int t a$ via, a Jermosura que tem, em Verso, \& Profa, \& os estrangeiros de Jenganados, da opinião que entre $\int i$ trazẽ, de serem as Juas muy auentajadas da

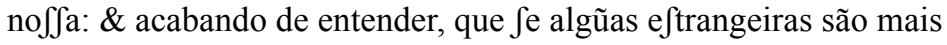
copiofas de palauras, que ella; tẽ a Portugue $\int a$ melhoria, em mostrar mayores conceitos, em a fua breuidade, que as mais em grande rodeo de palauras, \& nacer algũa falta de pollicia ( (e tégora a teue) da muita

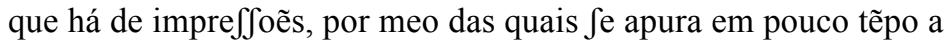
grofJaria dos Idiomas. (BRITO, 1597)

Note-se ainda que a referência ao francês no último verso pode aludir à origem francesa da família e/ou às pretensões francesas sobre o Rio de Janeiro que se faziam sentir no final do século XVII.

$\mathrm{O}$ segundo dado indireto que o cancioneiro nos fornece para a identificação do Cláudio Grugel do Amaral da folha de rosto está contido na Silva "Em aplauso do Autor" (f. 1-4v), escrita em castelhano e assinada por António Leitão de Faria. Não há no poema nenhuma pista biográfica, mas importa atentar em quem o assina. Segundo Álvaro Neves (1942), trata-se do filho de André Leitão de Faria, que viveu em Lisboa entre 1638 e 1722 e se destacou como poeta, calígrafo e pintor. Refira-se que os pais e os avós maternos de André eram naturais de São Salvador da Baía e que uma das testemunhas do seu casamento foi André Nunes da Silva, o destinatário atrás referido de uma carta de Cláudio Grugel. Ora, o filho de André, António Leitão de Faria, nasceu em 1684, em Lisboa (NEVES, 1942, p. 30), vindo a seguir as pisadas do pai: foi calígrafo e pintor, escrevendo também alguns poemas.

Com este dado, o processo de identificação de Cláudio Grugel do Amaral talvez não fique definitivamente fechado, embora as informações reunidas sejam bastante conclusivas. Se admitirmos que a Silva "Em aplauso do Autor" foi escrita por aquele António Leitão de Faria, somos obrigados a excluir o primeiro Cláudio, dado que em 1679 ele está de regresso ao Brasil e não consta que tenha voltado à metrópole. Torna-se pois provável que o Cláudio do cancioneiro manuscrito corresponda ao seu sobrinho, nascido no Rio de Janeiro três anos antes de António Leitão de Faria. O facto de este Cláudio, já em 1704 ser Procurador de Lisboa permite admitir 
a convivência entre os dois. Falta porém uma data para a composição da obra, embora a natureza paródica e burlesca dos textos pareça sugerir que se trata de um produto da juventude do autor, escrito possivelmente no início do século XVIII.

Identificado o presumível autor, passemos finalmente à obra, em que se reconhecem com facilidade estilemas barrocos, que sabemos dominarem ainda a literatura luso-brasileira do princípio de setecentos. O volume está organizado como um verdadeiro livro, como aliás se percebe pela caligrafia aprimorada, pelo alinhamento cuidado dos textos, pela utilização da cor em algumas palavras e letras ou pelas maiúsculas trabalhadas. A obra está dividida em três partes que, no seu conjunto, desenham um percurso sentimental e de vida.

A primeira delas, talvez a mais previsível (no sentido de mais próxima da linguagem lírica da época), apresenta o seguinte título:

Triumphos da Beleza/ Victorias do Amor/ Magestades da fermozura/ e Imperios de Sylvia/ Escreveos, dedicaos, e consagraos/ Lizardo/ A soberania, â pompa, ao Lustre, a gala/ Das Flores/ A Sylvia Triumphante/ Imprimeos/ De Lizardo o affecto/ A custa de seus Suspiros/ Em os bronzes/ Da Eternidade. (AMARAL, Ms. 354, f. IV)

Esta secção do volume comporta um total de 36 poemas, distribuídos pelas formas poemáticas mais comuns na época: 17 sonetos, nove romances, seis poemas em décimas, três madrigais e uma endecha. A escolha dos nomes do par amoroso não deixa dúvida quanto ao hipotexto (de acordo com a categorização de Genette) usado por Cláudio Grugel do Amaral: a Sílvia de Lisardo, de Frei Bernardo de Brito (*1568-9 †1617).

Publicada pela primeira vez em 1597, sem indicação de autoria, ${ }^{1}$ a obra voltaria a sair, já com atribuição a Frei Bernardo de Brito, em 1626 (Lisboa: Lourenço Craesbeck), 1632 (idem), 1668 (Lisboa: Joam da Costa) e 1784 (Lisboa: Francisco Luis Ameno). Os poemas que a integram terão sido compostos entre os anos 80 e 90 do século XVI, antes ou não muito depois de o autor ter entrado para a Ordem de Cister e professado, em 1585, no Mosteiro de Alcobaça.

\footnotetext{
${ }^{1}$ Mas com a atribuição feita por contemporâneos, como Manuel de Faria e Sousa e Manuel Severim de Faria.
} 
De orientação maneirista, a obra do polígrafo almeidense revela nítidas características do petrarquismo, sobretudo na parte inicial, correspondente às formas italianizantes (sonetos e églogas). Nela se inclui também o "Sonho de Lysardo, que he quafi como a Jegũda parte de Crisfal", em que a história do amor de Crisfal - que deixara de ser correspondido por Maria, ingressada num convento - é usada para estabelecer um paralelismo com o amor de Lisardo por Sílvia. A par desta, há também, como notou Nelma Patela da Silva, uma vertente, geralmente sob a forma de romance, que revela "uma certa ousadia e uma maior intensidade quer na vivência quer na forma de exprimir as emoções" (SILVA, 1998, p. 63).

Esta direção, por assim dizer dupla, é também acompanhada por Cláudio Grugel, que começa a obra num registo petrarquista - embora barroco, sobretudo na sintaxe -, dialogando às vezes de forma explícita com alguns dos poemas de Frei Bernardo. Veja-se os sonetos que servem em cada uma das obras de dedicatória, começando pelo do poeta português:

Soneto de Lysardo a ftas obras.

Versos, que indicio fois de meus ardores, Rima, que meus Jegredos publica $\int s t e s$, lagrimas, que tambem folemnizaftes, ao fom de andechas tristes minhas dores

Agora que vos veijo em mortas cores á vista do painel que retrataftes, gófto de vos olhar pois não leuastes a olhos eftrangeiros meus amores,

Se acontecer a ca $\int$ o, que entendida do mundo Jeija a dor, que em vós publico moftrai a caufa que ouue de renderme:

Que fendo dos leitores conhecida, verão que em me perder $\int \mathrm{em}$ culpa fico, $\&$ que fora mór culpa não perderme. (BRITO, 1697)

Vejamos agora o do autor carioca: 


\section{A Sílvia}

Dedicatória

Soneto

Estes triunfos teus, estas vitórias

de um amor firme, de ũa fé constante,

Lisardo, ó Sílvia, te oferece amante

quando ao mundo publica tuas glórias;

não escreve, bem sabes, vãs histórias, porém dessa beleza tão brilhante prendas ilustres, quando mais triunfante, consegue de Lisardo altas vitórias; ouve pois seus suspiros, que sentidos são os triunfos dessa gentileza[;] não sejam nos desdéns tão desabridos, nem nos rigores, menos na fereza como é o peito teu, os teus ouvidos, como é na condição tua beleza.

(AMARAL, 354, f. 5)

Há muitos outros casos em que o intertexto assume uma configuração semelhante, isto é, em que a alusão é de tal modo subtil que não permite detetar de imediato o diálogo entre os dois textos. É o caso do motivo clássico do retrato, que Frei Bernardo desenvolve com subtileza maneirista e ligeira ressonância camoniana:

Soneto em que diz, que quando $\int \mathrm{e}$ via nos olhos de Siluia achaua em Ji merecimento pera a querer, $\&$ aufentandofe o perdia de vifta.

Quando me vi nos olhos que me virão, veftido com librea d'efperança, cuidei que aquella cor era bonança, \& não q os proprios olhos ma veftirão.

E como difto alegre me Jintirão, por não dilatar mais tal confiança, fizerão em $\int i$ me $\int$ mos a mudança, que no lume dos meus logo imprimirão, 
Em fim, que quando em Siluia retratado

me vi, \& não em mim, achei comigo

baftante opinião pera querela:

Mas quando a não vi, de eenganado

fiquei, porque leuou ella configo

o preço, com que pude merecella. (BRITO, 1597, f. 3v)

Esta particular transformação do amador em cousa amada lembra ainda, por antecipação, uma passagem de No antigamente na vida de Luandino Vieira: "E eu olhei os olhos nos olhos dos olhos meus dentro dos dela." A réplica de Grugel sublinha, pelo contrário, uma espécie de dualidade entre significante e significado, entre retrato e alma, no quadro mais amplo do sofrimento de amor:

\section{A Sílvia}

Enjeitando um retrato a Lisardo

Soneto

A alma deste retrato não me entregas

quando mo entrega teu desdém ingrato,

pois se a efígie te dei deste retrato,

a alma que te entreguei nele me negas;

neste lance tão vil, ingrata, alegas

o que esta alma padece em teu mau trato,

pois entregando-ta eu a teu recato,

fica em ti e do retrato te despegas;

a alma, enfim, te entreguei, nesta pintura[;]

esta me entregas, tens naquela a palma[;]

que importa logo pois que em sorte dura

me enjeite do rigor em brava calma

este retrato tua fermosura,

se em ti, Sílvia cruel, me fica a alma?

(AMARAL, 354, f. 6v)

A lista de casos poderia ser aumentada. Frei Bernardo tem, por exemplo, um "Soneto que Lysardo fez a Siluia em dia de Pa ccoa, eftando aufente della, \& tendoa vifto a noite da Paixão." (BRITO, 1597: f. 16), ao 
passo que o poeta do Rio apresenta outro "A Sílvia/ Trazendo ũas flores na mão ũa manhã de Páscoa" (AMARAL, 354, f. 27v). Refira-se que, já nesta primeira parte do volume manuscrito, há momentos em que o diálogo intertextual assume contornos paródicos. Confronte-se o "Soneto feito a Silvia, porque eftando ennaftrando os cabellos em hum jardim, veo hũa grande tempestade." (AMARAL, 354, f. 17) com um poema em décimas de Cláudio, dedicado "A Sílvia/ Estando sonolenta à vista de Lisardo e espertando a uns trovões" (AMARAL, 354, f. 21v-22v), o qual apresenta um nítido teor burlesco, como se percebe da seguinte passagem:

\author{
Estou para vos dizer \\ desta raiva em a paixão \\ que tomara ser trovão \\ para acordada vos ter; \\ pois que à vista de um querer \\ com sono estais, minha flor, \\ donde infere a minha dor \\ que para tal formosura \\ tem um trovão mais ventura \\ do que forte o meu amor.
}

De resto há nesta secção inicial muitos momentos em que a representação mais ou menos petrarquista da amada resvala para o plano carnal e adquire um tom licencioso, bem mais carregado pois que a sugestão erótica que vai aparecendo na parte final da obra de Frei Bernardo de Brito, geralmente sob a forma de romance. Vejamos duas passagens de uma endecha (f. 31v-35):

As tetinhas alvas,

filagranas todas,

da mais alva neve

(minha Sílvia) zombam.

Manjar branco em pelas

nessas tetas mostras,

que muito as desejam

vontades gulosas.

[...] 


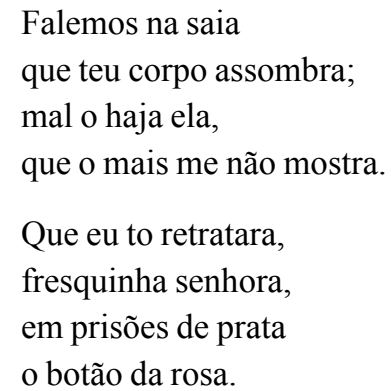

(AMARAL, 354, v. 41-48; 89-96)

Mas é na segunda parte do volume manuscrito que o registo paródico é definitivamente confirmado. Usando de forma sarcástica o motivo clássico do amante enganado, os textos dão conta do fracasso da relação amorosa entre Lisardo e Sílvia, devido à traição da dama, que percebemos agora ser freira. O título anuncia com clareza a mudança de registo:

Cornucopia/ Que em o congreço Poetico/ dos famozos Academicos nocturnos/ Selebremente, seteçeo/ Em os selebrados cornos, q pos a fermoza/ Sylvia/ A seu amante, Lizardo/ Offereçea, e dedica a/ O Dezengano/ A todos os Amantes, mentecaptos, Basbaques/Anciozos Tantalos, e/ âerios cameliões/ Em os enganozos amores de Freyras/ Imprimios/A Disquirição./ A Custa dos mesmos Nescios. (AMARAL, 354, f. 46)

Segue-se uma paródia dos elementos habituais numa edição impressa: um soneto em que Apolo manda rever os poemas "A Trajano Bocalino, como a censor do Parnazo" (AMARAL, 354, f. 47); um outro em que Bocalino dá conta da censura que fez (f. 47v); outro em que Apolo dá a licença para a impressão (f. 48); outro com a "Taxa que a Meza do Paço de ElRey Apollo pos a este Livro." (f. 48v); a dedicatória “Aos Senhores amantes Freyraticos." (f. 49); um soneto enviado do Inferno por Marcial "Aos Senhores Academicos Nocturnos" (f. 49v); o soneto de resposta "pellos mesmos consoantes." (f. 50); e, por fim, um soneto "Ao pio E devoto Leytor." (f. 50v).

A Cornucópia propriamente dita é formada por quatro poemas que dois amigos e algumas damas dirigem a Lisardo: uma silva, um romance, um poema em décimas e uma endecha. A título ilustrativo, vejamos uma passagem do romance (AMARAL, 354, f. 57v-58r): 


\author{
Convosco falo, Lisardo, \\ porque falando convosco \\ cornos tudo são que vejo \\ e cornos tudo o que topo. \\ Cornos fêmeas, cornos machos, \\ cornos grandes, cornos mochos, \\ cornos grandes e piquenos, \\ cornos delgados e grossos. \\ Cornos com nós de Boi velho, \\ cornos de veado e cornos \\ de carneiro e de cabrão, \\ cornos que não tem já conto. \\ E são tantos que podeis \\ ter os timbres bem famosos \\ dos Duques de Cornualha \\ e mais dos Cornélios todos. (v. 25-40)
}

A terceira e última parte do volume constitui uma espécie de resposta de Lisardo à sátira anterior. O primeiro texto é uma longa dedicatória em prosa: "A S.${ }^{\text {ra }}$ Catherina do sacram. ${ }^{\text {to }}$ Dedica, offerece, e consagra/ Lizardo./ Os Triumphos de sua Belleza." (AMARAL, 354, f. 67-71v). Segue-se um outro texto em prosa, ainda mais extenso, intitulado "Advertencia Appologetica./ Rezão Satisfatoria/ Discurso demostrativo, deste empenho./ As Senhoras/ q curioza mente lerem/ Estes Tropheos de amor, em os Triumphos/ da mayor Beleza." (f. 72-101). Nele, o sujeito, lamentando a sátira de que Sílvia fora objecto, narra um sonho em que se vira no Pindo, aí encontrando os autores da Cornucópia. Tal como eles, também o narrador, que se chama Artimidoro, ${ }^{2}$ é preso e levado à presença de Apolo, acusado de ter sido o pretexto dos crimes de que todos são acusados: a prática da sátira e da poesia lasciva. Condenados inicialmente a casarem com as damas que tinham apresentado queixa a Apolo, acabam por ver a sentença comutada: são suspensos “das ordens de Poetas, mandando as Musas os não socorram

\footnotetext{
${ }^{2}$ Nome certamente inspirado em Artemidoro de Daldis (ou de Éfeso), oniromante e adivinho grego, que viveu da segunda metade do século II d.C. e que escreveu um livro sobre a interpretação dos sonhos.
} 
com nenhuns consoantes, sob graves e terríveis penas, por tempo de dous Anos" (f. 100r). São também enviados, pelo mesmo período de tempo, para a nova conquista do Monomotapa, ao passo que as queixosas são mandadas recolher a um convento. O narrador recebe ainda a ordem de queimar a Cornucópia e de louvar Sílvia em verso, sob o nome de Lisardo.

Como se percebe, estamos agora mais longe do hipotexto da Sílvia de Lisardo: se é verdade que o motivo do sonho e da freira dialogam com o "Sonho de Lysardo, que he qua 1 i como a egũda parte de Crisfal", a viagem ao Parnaso terá outras fontes. O tema aparece com frequência na literatura clássica, sobretudo espanhola. Basta recordar Viaje del Parnaso de Cervantes (1614), Laurel de Apolo de Lope de Vega (1630) ou El Sacro Parnaso de Calderón de la Barca (1659). Na literatura portuguesa também se mantém até tarde, como se pode ver pelo poema joco-sério de finais de setecentos $A$ Josefinada, de Manuel Rodrigues Maia (Cf. AMARAL, 2011).

A parte final do volume de Cláudio Grugel é ocupada com o cumprimento da sentença de Apolo: ao longo de 18 poemas (oito romances, oito poemas em décimas e dois sonetos), Lisardo louva D. Caterina do Sacramento, voltando-se assim ao ponto de partida e encerrando a obra no mesmo registo elevado e engenhoso com que começara. Sirva de exemplo a primeira estrofe de um poema em décimas:

À mesma Senhora tendo na toalha ũas Flores secas

Décimas

Se ao sol da vossa beleza

essas flores não murcharam,

com menoscabos ficaram

dessa sua gentileza;

pois murchando com destreza

de tal beleza ao farol,

mostraram que no arrebol

de tal sol nos resplendores

eram, Caterina, flores,

e vós um luzido sol.

(AMARAL, 354, f. 116v-117v, v. 1-10)

Chegando ao fim desta breve apresentação de um trabalho ainda não acabado, não é fácil extrair uma conclusão sobre o sentido da paródia: Que 
visa esta imitação cómico-caricatural de uma obra ainda canónica no século XVII? Trata-se de uma forma de homenagem ou de uma crítica carnavalesca aos valores que ela representa ou ainda de uma atualização bem-humorada dos amores freiráticos tão presentes na literatura barroca? A resposta exigirá mais trabalho e a disponibilização ao público da edição, que trará para a literatura luso-brasileira uma nova voz, com o seu quê de irreverente.

\section{Referências}

AMARAL, Andreia. A “Josefinada” de Manuel Rodrigues Maia: um poema joco-sério sobre um caso de plágio no final de setecentos. Lisboa: Fundação Calouste Gulbenkian / Fundação para a Ciência e a Tecnologia, 2011.

AMARAL, Cláudio Grugel do. [Correspondência]. Destinatário: Dr. André Nunes da Silva. André Nunes da Silva. Rio de Janeiro, 25 jun. 1679. Biblioteca Nacional de Portugal, Ms. 245, n. 141.

AMARAL, Cláudio Grugel do. Ad Inchoanda Scholastica Certamina. Conimbricae: Iosephum Ferreyra, 1675.

AMARAL, Cláudio Grugel do. Monte do Apolo: Parnazo das Muzas: Obras variadas de Claudio Grogel do Amaral. Recopiladas por Ezope de Homero Mendes. Biblioteca Geral da Universidade de Coimbra: Ms. 354. [S.l.], [167-?]. Tomo 15.

AMARAL, Heitor Luís Grugel do. Uma Família Carioca do Século XVI. Rio de Janeiro: São José, 1964.

BRITO, Frei Bernardo de. Silvia de Lysardo em que ha varios Sonetos, \& Rimas, com a segunda parte do Sonho de Chrisfal. Agora novamente impressa, \& posta em ordem por Alexandre de Siqueira, Impressor de livros. Lisboa, 1597.

MACHADO, Diogo Barbosa. Bibliotheca Lusitana Historica, Critica, e Cronologica. Tomo I. Lisboa Occidental: Officina de Antonio Isidoro da Fonseca, 1731.

MARCOS DE DIOS, Ángel. Os portugueses na Universidade de Coimbra desde a Restauração até às reformas iluministas do Marquês de Pombal. Salamanca: Luso-Española de Ediciones, 2001. 
MENDES, Nuno Canas. Do Brasil para Portugal: itinerários genealógicos de dois ramos da família Amaral Gurgel. Genealogia \& Heráldica. Porto, n. 3, p. 233-237, 2000.

MORAIS, Francisco. Estudantes da Universidade de Coimbra nascidos no Brasil. Brasília, v. IV - Suplemento: Publicação Comemorativa do Quarto Centenário da Cidade do Salvador; Coimbra, 1949.

NEVES, Álvaro. "Eques Faria Filius" é António Leitão de Faria: processo de identificação do calígrafo e desenhador do século XVIII. Lisboa: Bertrand, 1942.

SILVA, Nelma Cristina Mesquita Gomes Patela Cardoso da. Sílvia de Lisardo: edição e análise do texto. 1998. Dissertação (Mestrado em Literatura Portuguesa -Época Medieval e Clássica) - Faculdade de Letras, Universidade de Lisboa, Lisboa, 1998.

TOPA, Francisco. Nas origens da literatura brasileira: um poeta lusobrasileiro desconhecido. Navegações: Revista de Cultura e Literaturas de Lingua Portuguesa, Porto Alegre; Lisboa, v. IV, n. 2, p. 167-171, 2011.

Recebido em: 12 de janeiro de 2020.

Aprovado em: 13 de abril de 2020. 